\title{
An Information Professional Personnel Training Mode Based on Social Requirement of Independent Colleges
}

\author{
Jinjiao Lin \\ Yanshan College of Shandong University of Finance and \\ Economics \\ Jinan, China \\ e-mail: linjj112@163.com \\ Minqu Fan \\ Shandong University of Science and Technology \\ Jinan, China \\ e-mail: fmq@sdust.edu.cn
}

\author{
Haitao $\mathrm{Pu}$ \\ Shandong University of Science and Technology \\ Jinan, China \\ e-mail:pht@sdust.edu.cn
}

\section{Jun Li}

Yanshan College of Shandong University of Finance and Economics

Jinan, China

e-mail: email0708@163.com

\author{
Jian Lian \\ Shandong University of Science and Technology \\ Jinan, China \\ e-mail: lianjianlianjian@163.com
}

\begin{abstract}
In recent years, whether the graduate are needed by the society has become more and mor concerns. In this paper, combining the students of independent colleges and our education practice, the social requirement oriented training mode is proposed. we construct and improve the pattern both conforming the practical needs of current economic society and reflecting the training characteristics based on the social requirement for Information Management and Information System talents of different majors and levels.
\end{abstract}

Keywords-information management and information system, personnel training mode, social requirement, independent college

\section{INTRODUCTION}

Personnel training mode, which determines the basic characteristics of the trained object, is the specific implement way of colleges and universities to train the students' knowledge, ability and quality structure. Personnel training mode based on social requirement enhances the pattern with social requirement oriented education construction and talent management, meanwhile implement the suitable principles and flexibility in the whole process.

In recent years, the employment for graduates has become one of the major concern of the society. Essentially, the problem is related to structure rather than quantity. And the main reason is that for these years, the major setup and training mode always follows the supply oriented principle, which causes the divorce between major setup and market requirement. Traditional Personnel training mode, knowledge structure and quality structure cannot satisfy the practical needs of our economic development. Therefore in order to solve the problem we should focus on making use of the information from labor market, construct and create the requirement oriented personnel training mode according to social requirement principle and improved high education system. In other words, the education department should adjust the content of subject, major and course in time, which can satisfy the market requirement, based on the dynamical market demand. Obviously, to construct the market signal generation mechanism, transmission mechanism and adjustment mechanism, we need the construction of requirement oriented education mechanism and creative personnel training mode.

At present, knowledge economy trains and develops rapidly with brand new gesture, and goes through explosive expansion. Following the hierarchically development of new technology revolution and continuous change of economy structure, even in rapidly developed information management field the employment situation of graduates is terrible now, and intense competition, overall quality and society adaptability have become the most important factors in information management talent requirement and competition[2]. Under the situation discussed above, the overall information management major talents who has complete knowledge structure, acute creative consciousness and spirit, perfect personality and strong society adaptability, can be competent the corresponding position and be accepted by the market. Therefore, in the education practice in financial colleges, we should pay attention to the economic development frontier and grasp the market requirement direction, which can help us to construct and improve the pattern in order to conform the practical needs of current economic society, reflect the training characteristics based on the social requirement for Information Management and Information System talents of different majors and levels. 


\section{RESEARCH STATUS}

Currently, there have been plenty of discussion and researches relative to personnel training mode [3,4]. In general, the pattern includes three main factors: teaching principle, teaching pattern and culture environment. Most of the researches insist that the talent training in colleges and universities should focus on following aspects: to face the society reality, to stress interdisciplinary and ability, to enhance practice, to cultivate team spirit and creativity.

At present the problems in researches on information management and information system personnel training mode are:

\section{A. Fuzzy professional positioning}

In "Specialty catalog and introduction of undergraduate course of common colleges and universities" presented by Chinese Ministry of Education[1], the training objectives of information management and information system have been given thoroughly, but the content is highly generalized and broadly. Many professional teachers in universities would misunderstand the content in the making process of major training plan and teaching outline, which makes the students of this major especially the freshmen confused about the subject development and future occupation direction. At the same time, many teachers in information management and information system originally are from management major or computer major, so they usually they would start from the original major stand and divide the new major into management and computer parts. But practically, information management major not only needs computer based information technique courses but also stress the ability of management information system design and implementation.

In the professional talent training process, most of the plan and course architecture in colleges and universities have flaws. Firstly, the courses arrangement, most of which have not arranged the guide courses and subsequent courses as knowledge acquirement behavioral habit. Secondly, they do not pay attention to practice teaching, and neglect the interdisciplinary features of the major, which all make the students lack of the ability of knowledge application and necessary means of comprehensive ability. Thirdly, the connection between the major courses is not deep enough, especially between the fundamental theory and information technique courses, which make the students hard to apply their knowledge in design and implementation, confines the enhancement of their ability.

Analyzing from the practical perspective, information technology has been applied broadly in modern enterprise management, and the management concept, ideas and means have changed totally. Information technology has also deeply affected every aspect of the current economic society. So how to train students, who have rapid adaptability to science and technology development and conform to the society requirement, is one of the important projects in information management major talent train.

\section{B. Chaos pattern}

Now the information management major positioning mainly relates to three kinds of courses: the first kind is general education courses, such as: higher mathematics, foreign languages and political courses; the second kind is economy management courses, such as: Management, Economics, Accounting and Financial Management; the third kind is information technology courses, such as Programming, Operating System, Networking and Database, etc. And in this pattern there is no effective interdisciplinary professional course architecture, but the courses are simply meld, the connection between them is not solid and the knowledge architecture is incomplete, too. And the information management and information system major train plans of the colleges and universities are different from each other, and the perspective differs, too. In "Specialty catalog and introduction of undergraduate course of common colleges and universities" of 1998, the courses includes: Economics, Accounting, Marketing, Operation Management , Organizational strategy and behavior, Principle of Management, Application of mathematical statistics, Operation research , Computer system and software, Data structure and Database, Computer networking, Information Management, Information Organization, Information storage and retrieval, Management Information System analysis and design, etc[1]. And the courses should be divided into following modules: economics knowledge module, management knowledge module, computer knowledge module and information management knowledge module, each college and university has their own opinion to the plan.

In the plans, the colleges and universities have agreed that there should be fundamental quality knowledge module, modern information knowledge module, information management and information system major knowledge module and major background knowledge module in the final plan, through which we can understand that the main objective of major training is to construct the systematic structure of major knowledge.

\section{Lack of laboratory fundamental condition and insufficient of labs and practical training}

Information management and information system major has the characteristics of binding of theory and practice, which demands practical experience of the teachers. But nowadays most of the teachers graduating from University directly have no practical engineering experience. Because most of the teachers have no way to attain information implementation means in practice, and they can only carry our theory teaching, which makes the students lack of practical experience, either. And they cannot understand the importance information technology. Therefore, major teachers without knowledge renovation and practical experience are the most terrible problem now. And most of the persons incorrectly assume that the information management major belonging to management science, and misunderstand the major laboratory of the major. Actually, comparing to Science and engineering laboratory, lab of management major has more input and less output. Therefore, the University prefers to construct the former labs instead of 
management major labs. And, some of the Universities treat the theory teaching staff and experiment staff differently in salary and other aspects, which severely damage the working enthusiasm of the lab staff. Because of the existing problems above, the construction of the information management labs obviously lags behind the society requirement to talent training, which makes it hard to carry out in talent training.

\section{Reform plan design}

We can find that the information management and information system major relates to many different fields, and because of the rapid development, hard work of teaching tasks and insufficient time of major courses, which all make creative major teaching reform and construction important.

1) Reform courses in information technology module

To carry out corresponding reform to courses in information technology module, this can help the students to make use of information technology effectively. Meanwhile we should adapt the knowledge learned from management courses into practical scenarios such as: reflecting the running situation of enterprise, management and decision, and combine the knowledge learned in mathematics courses within. And the combination of the several modules can be used to analyze and solve the problems.

\section{2) Reform practical teaching segment}

Surrounding the industry background and professional training objectives to build all kinds of practice teaching link, and combine them into practical teaching link, which can be used to enhance the basic practical ability, professional adaptability and creativity of the students, to improve and reform the present information management and information system major practical teaching objective architecture, practical teaching content architecture, practical teaching management architecture and practical teaching quality evaluation architecture.

3) Reform and create teaching methods

We should renovate teaching concept, motivate the students to think more, analyze more and enhance the practical ability of them. Making use of modern teaching methods and tools, we would attract initiative of the students. In course teaching process, we should pay more attention to foster self learning ability, creativity ability and independent thinking ability of the students. In class teaching process, we should insist on the combination of theory and engineering cases to enhance the comprehensive ability to apply the knowledge in practice of the students.

\section{E. Solution methods}

We present the following methods based on the reform plan above

1) Select the textbooks and reference books.

We should choose one set of textbooks and reference books which are suitable for the situation of our University and pay attention to the connection between the textbooks themselves. The selection of textbooks is important, and they would affect the students a lot in a course.Reform courses in information technology module

2) Emphasize on fundamental theory teaching, arrange curriculum schedule reasonably.

We should emphasize the fundamental courses, major core courses and lab courses, enhance the coaching answering $s$ and paper correction, and choose the experienced teachers to teach the fundamental courses. According to decades of teaching experience, whether the student would become the talent that the market and society needs the first year is rather important. Besides public courses, the subject characteristics determines the freshmen should put most of the energy on fundamental courses such as mathematics, rather than computer operations, programming design, etc. Listening to the teachers carefully, reading, thinking hardly and experiencing deeply, which all need repeatedly boring learning, are the main parts of the freshmen. Many students have not gone through systematical and hard fundamental learning and training, which leads to Infineon when they enter higher grade. But once one student finish the fundamental learning process, even if his entrance scores is lower than other students, he would catch up the others definitely and he would feel easier in the following courses. The reason is that this kind of students have followed the requirement of the major and gone through fundamental training hardly.

3) Reform evaluation means. Information management and information system major has dual characteristics of theory and application, and the evaluation of core courses is important to students.

We should advocate better learning atmosphere, relying on scientific credit management principle, to embody the theory learning and knowledge application and make sure the fairness, objectivity and credibility.

4) Enhance the lab teaching process and standardize the experiment teaching process.

Based on fundamental courses teaching, targeted and scheduled to enhance the lab teaching in the major, and foster the combination ability of theory and practice.

\section{CONCLUSION}

Information Management and Information System is one of most necessary major in our information-base society, because we need information in all walks of life. In this paper we propose the personnel training mode for Information Management and Information System major through theory and practice. We hope that the pattern can enhance the society adaptability of students from this major.

\section{ACKNOWLEDGMENT}

This work has been supported by the Shandong Science and Technology Development Project (2012GGX10122, 2013G0021109), the Shandong Province Higher Educational Science and Technology Program (J11LG21, J13LN35), Jinan Science and Technology Development Project 
(201202058), Teaching Reform of the Key Project of Shandong Province (2012073,2012552,2012033) and International Cooperation Program for Excellent Lecturers by Shandong Provincial Education Department, and Teaching Research Project of Shandong University of Science and Technology (qx2013286)

\section{REFERENCES}

[1] Department of Higher Education, Ministry of Education of P.R.China, Specialty catalog and introduction of undergraduate course of common colleges and universities. Beijing: Higher Education Press, 1998.

[2] Wu Qing, Yu Xiaobing, Gen Yan, Liang Xue,”Comparison and Anylase on Training Mode of Information Management Information System between China and American”,Journal of China Management Information,2013,16(1).

[3] Tao Qing, "Researches on Foreign Universities MIS Course Construction” in Modern Information, 2006,(7), pp.195.

[4] Naidong Zhao, Feng Wang,"China-Foreign Comparison on Training Mode of Information Management Information System Major”, Journal of China Management Information, 2000,13(17). 